\title{
Fatigue Life Analysis of Upper Arm of Wishbone Suspension System
}

\author{
B. Sai Rahul ${ }^{1}$, D.Kondaiah ${ }^{2}$ and A.Purshotham ${ }^{2}$ \\ ${ }^{1}$ M.Tech. Cad/casm student : SreeNidhi Institute Of Science and Technology,Hyderabad-501301, India. \\ ${ }^{2}$ Faculty of Mech.Engg. SreeNidhi Institute Of Science and Technology,Hyderabad-501301, India.
}

\begin{abstract}
The wish bone suspension system is one of the most used suspension systems of automobile vehicles. Its dynamic behavior directly affects the safety, performance and, noise level.The lower and upper arms of wish bone are the main critical elements. This paper describes the analysis of upper arm of wishbone using softwares namely Catia and Hypermesh. The objectives of this study are to characterize the dynamic behavior and to investigate the fatigue life of upper suspension arm. Control arm(Upper arm) is designed in $3 d$ modeling Catia software and then imported in to Altair Hypermesh for finite element modeling.The solutions of dynamic analysis obtained.The overall aim of the paper is to estimate the fatigue life of control arm. The results, thus obtained, can significantly reduce the cost and time to market, improve product reliability and customer confidence.
\end{abstract}

Keywords: Suspension system, Control arm, Fatigue life, Hypermesh.

\section{Introduction \& Literature SURVEY}

Suspension system is a system that consists of springs, shock absorbers and linkages that connect vehicle to its wheels. Vehicle suspension systems serve a dual purpose which are contributing to the road handling and braking devices for increase the safety and driving pleasure, and also keeping vehicle occupants comfortable and reasonably well isolated from road noise, bumps, and vibrations. The acceleration of the vehicle body can determine ride comfort and the task of the suspension system is to isolate disturbances from the vehicle body, which caused by the uneven road profile. The wheels ability to transfer the longitudinal and lateral forces onto the road can affect the safety of the vehicle while traveling. The necessity of the vehicle suspension system is to keep the wheels as close as possible the road surface. Wheel vibration must be damped and any dangerous lifting of the wheels must be, as far as possible, avoided. The body of the vehicle is mostly isolated from high frequency disturbance of the road by the suspension system. When there is a change in loading, the suspension system should be able to keep the vehicle level as stable as possible, so that the complete suspension travel is available for the wheel movements [1]. Ingeneral, there are three types of the suspension system which are passive, semi-active and active suspension system. The conventional suspension system is passive suspension system. springs and dampers are two major elements of this type. The purpose of the damper is to dissipate the energy and the spring is to store the energy [2]. For this type of suspension system, damping coefficient and spring stiffness is fixed parameters. Design of a robust suspension lowerand upper are arm are crucial to the success of manufactured the car and requires that suspension components have to be well in aspects of both compactness and crashworthiness.

This paper is organized in the following manner: Section 2 gives the detailed modeling of geometry of upper arm of wishbone. Section three discusses simulation results obtained fro the softwares used. Conclusions are drawn in section 4 .

\section{Geometric Modelling Of Upper Arm}

In this section the upper control arm of wish bone of Maruthi omni car is modeled using CATIA V5 R19 Software. The 2D drawings of upper arm are shown in figure 2.1 and its 3dimensional figure is shown in figure 2.2. The mesh model of the upper control arm is worked out in hypermesh and it is shown in figure 2.3 


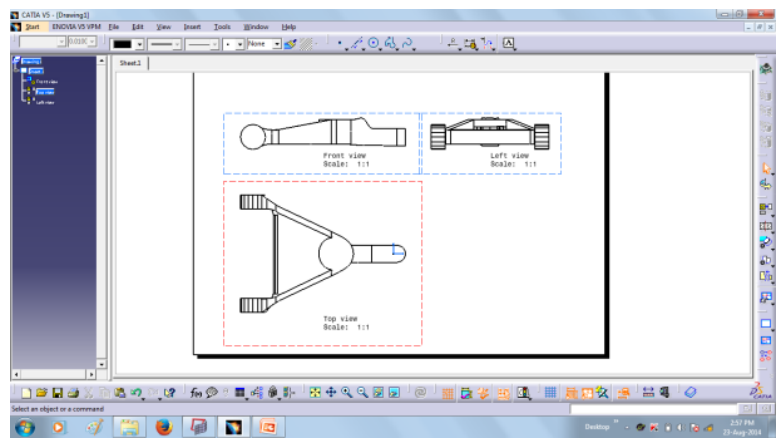

Figure 2.1 Control Arm drawing

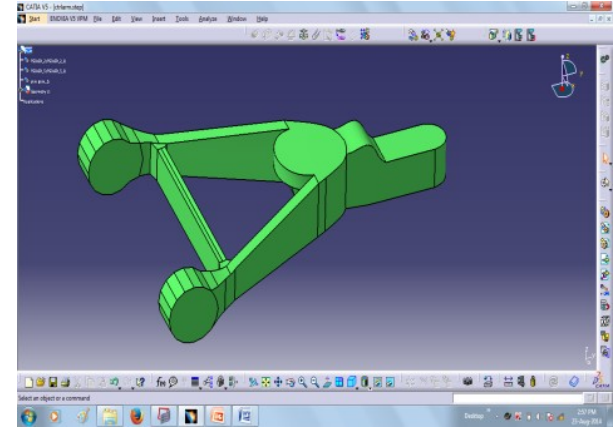

Figure 2.2 3D of Control arm arm

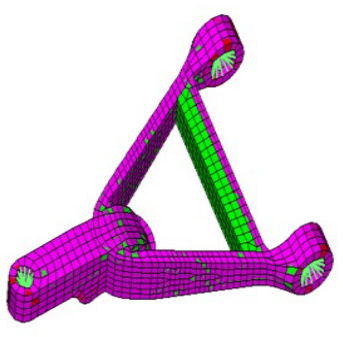

Figure2.3 : mesh model of control

\section{Simulation Results And Discussions}

In order to study the dynamic characteristics of upper arm of wish bone, the parameters of upper arm of omni have been taken. These parameters are shown in table 3.1

Table 3.1: Basic Parameters of for dynamic simulation

\begin{tabular}{|c|c|c|c|c|c|}
\hline $\begin{array}{c}\text { Total weight } \\
\mathbf{K g} \\
(\mathbf{G})\end{array}$ & $\begin{array}{c}\text { Weight on front end } \\
\mathbf{k g} \\
(\mathbf{G f a})\end{array}$ & $\begin{array}{c}\text { Weight on rear } \\
\text { end } \\
\mathbf{k g}\end{array}$ & $\begin{array}{c}\text { Wheel base } \\
\mathbf{m m} \\
(\mathbf{G r a})\end{array}$ & $\begin{array}{c}\text { Dist from front } \\
\text { axle to center of } \\
\text { gravity } \\
\mathbf{m m} \\
\text { (Lf) }\end{array}$ & $\begin{array}{c}\text { Dist from front axle } \\
\text { to center of gravity } \\
\mathbf{m m} \\
(\mathbf{L r})\end{array}$ \\
\hline 1725 & 907 & 808 & 2472 & 1289 & 1453 \\
\hline
\end{tabular}

The braking force of the vehicle depends on the frictional force of the vehicle when it moving on the road. The maximum value of frictional force is $\mu \mathrm{W}=0.236 * 17250=400 \mathrm{KN}$.

This force is considered as Fatigue force (cyclic load) and it is modeled as shown in figure 3.1

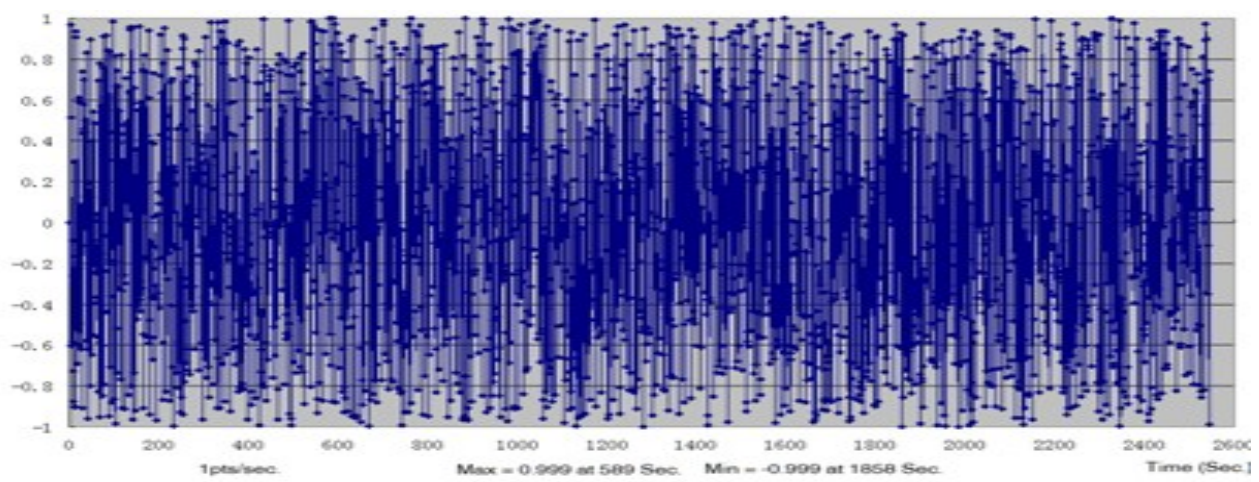

Figure 3.1: Braking force

For Transient analysis, the braking force taken on the arm is modeled as shown in figure 3.2 


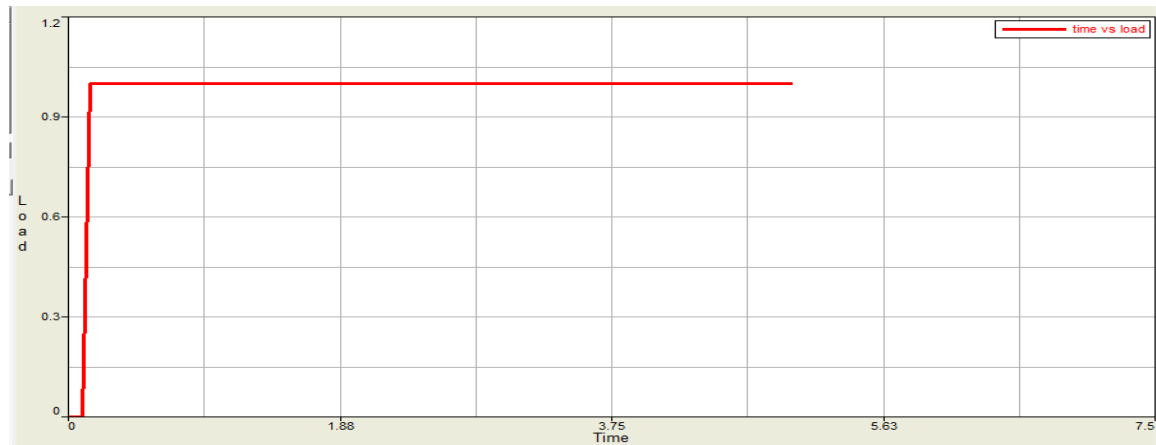

Figure 3.2 :Braking force-time

The reaction of the vehicle is considered for simulation study is vertical force which has magnitude of $500 \mathrm{KN}$. 3.1 Static Stress And Deflection Analysis :

When a vertical force $5000 \mathrm{~N}$ in vertical direction is applied ton the arm, stresses and deflections are developed and they are shown in figures .3.1.1 \&3.1.2

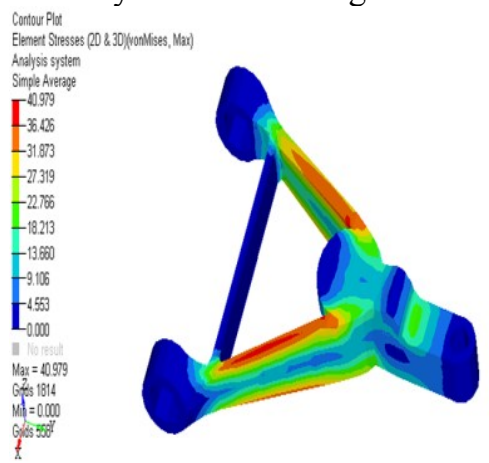

Figure 3.1.1 Maximum Stress for model-1

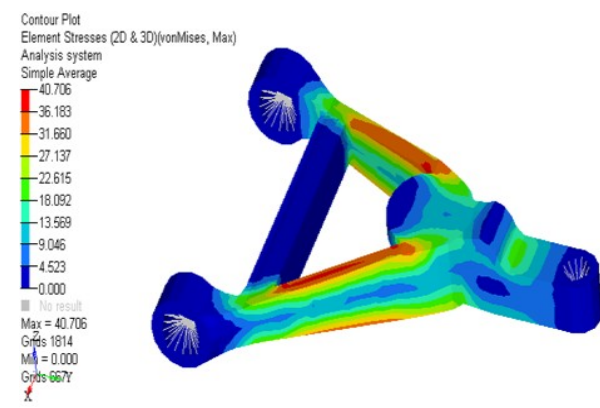

Figure 3.1.2 Maximum Stress model -2

When a maximum force of $4000 \mathrm{~N}$ applied in moving direction of the vehicle, the stressesand deflection developed are shown in figures 3.1.3 \&3.1.4

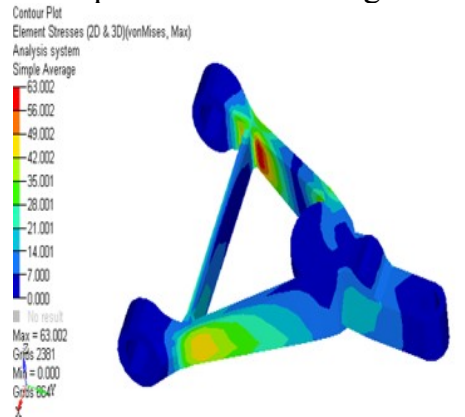

Figure 3.1.3 Maximum Stress (Brake force) force)

3.2 Fatigue Analysis

When the arm subjected to cyclic load as mentioned above, the fatigue life found to be $1 \mathrm{E}+16$ and this is shown in figure 3.2.1

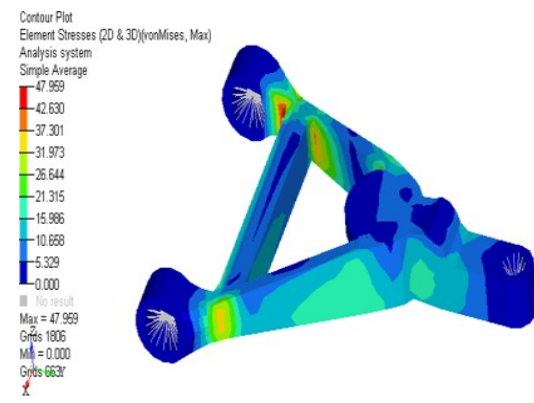

Figure 3.1.4 Maximum Stress model -2 (Brake

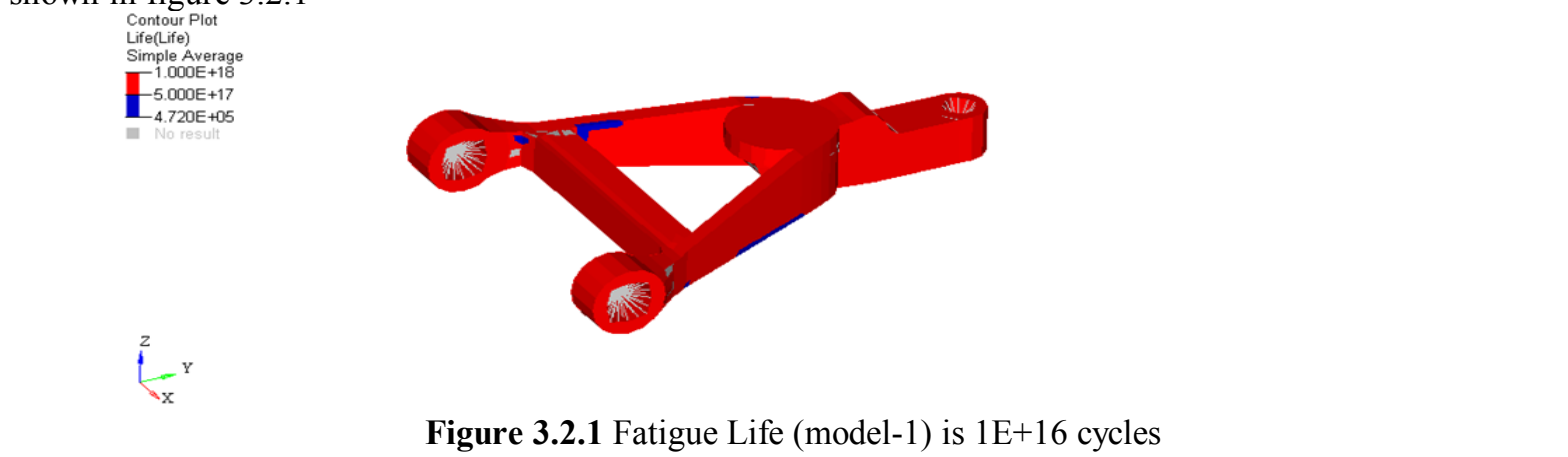




\subsection{Transient Analysis}

When arm is subjected to braking force for shorter time, the transient response of upper arm is being extracted with Alter optistruct software. The transient results of upper arm are shown in from figure 3.3.1 to figure 3.3.3

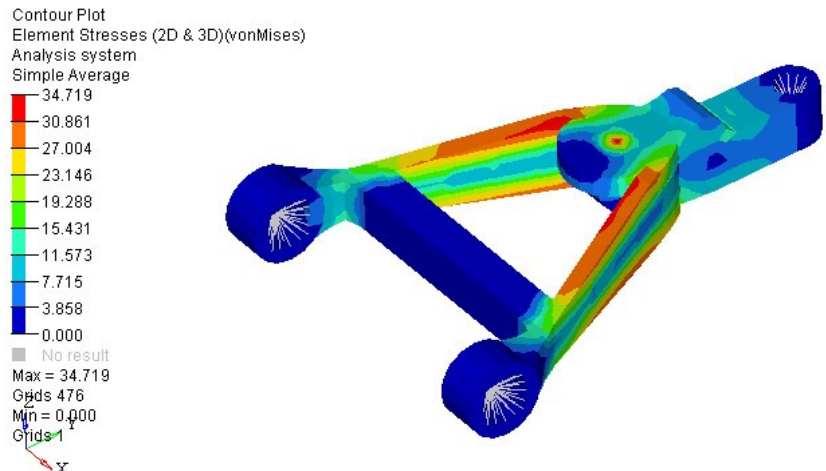

Figure 3.3.1 Stress is $34.719 \mathrm{Mpa}$ at 4 seconds of time

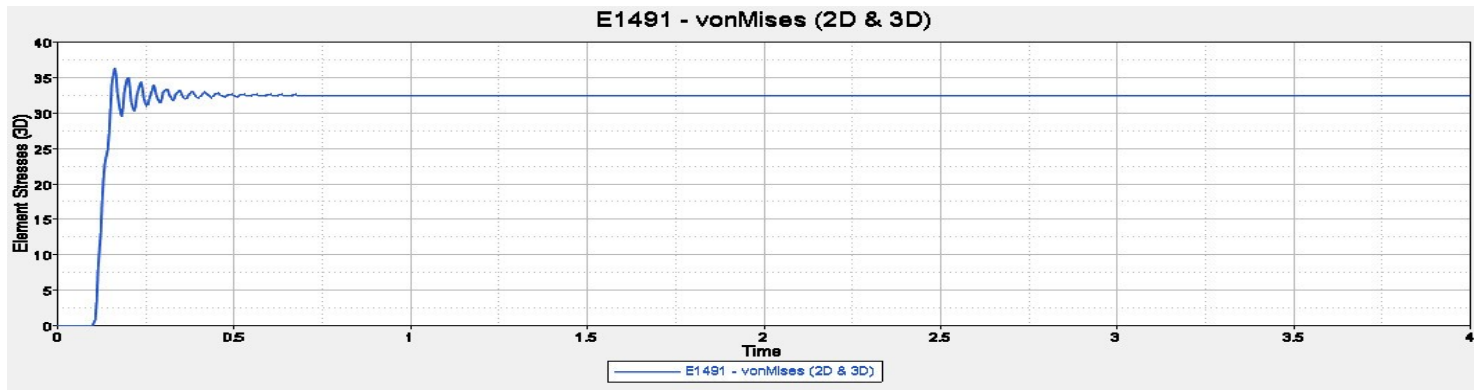

Figure 3.3.2 Graphical plot of element with peak stress Displacement

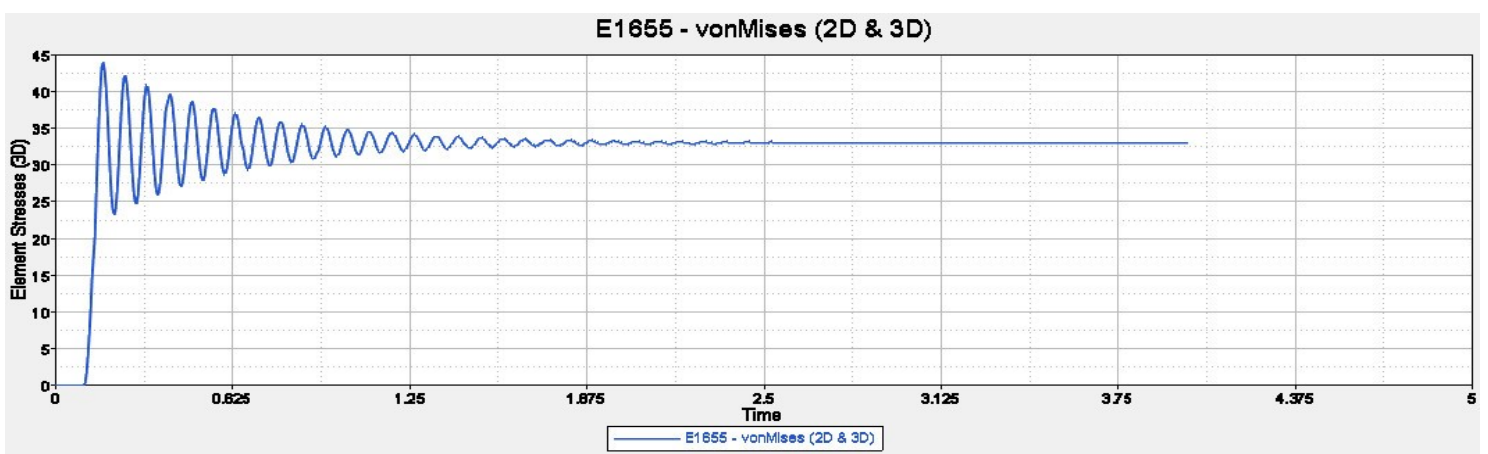

Figure 3.3.3 Graphical plot of element with peak stress Displacement

The simulated values are also shown in the tables 3.3.1 to 3.3.3

Table 3.3.1: Stresses and deflections for vertical analysis

\begin{tabular}{|c|c|c|}
\hline & Maximum stress Mpa & Maximum displacement mm \\
\hline Model 1 & 40.979 & 0.767 \\
\hline
\end{tabular}

Table 3.3.2: Stresses and deflections for brake force analysis

\begin{tabular}{|c|c|c|}
\hline & Maximum stress Mpa & Maximum displacement mm \\
\hline Model 1 & 63.002 & 0.986 \\
\hline
\end{tabular}

Table 3.3.3: Fatigue Life of the arm

\begin{tabular}{|c|c|c|}
\hline & Maximum (cycles) & Minimum(cycles) \\
\hline Model 1 & $1.00 \mathrm{E}+16$ & $3.88 \mathrm{E}+04$ \\
\hline
\end{tabular}

\section{Conclusions}

In this paper the upper arm of a wishbone suspension system is analyzed for its fatigue life and transient behavior when a braking is initiated on the automobile. Altair hypermesh with catia modeling methods have been exhaustively used in obtaining the simulation results. Based on the simulation results, it is 
concluded that the arm of wish bone posses good fatigue life which is $10^{16}$ cycles and transient behavior with maximum peak stress value is 34MPa. These stress values are less than the material (Aluminum) of Wishbone in less time.

The overall objective of this paper is to apply CAD tool to get the dynamic behaviour at low cost and

\section{References}

[1]. Mohd Rizal Bin Ahmad and Manap, 2007, "Simulation and Experimental Analysis of an Active Vehicle Suspension System,"Master Thesis. University Teknologi Malaysia.

[2]. Adizul Ahmad, 2005, "An Observer Design for Active Suspension System," Master Thesis. University Teknologi Malaysia.

[3]. Altair Engineering. "OptiStruct 7.0 User's Guide.” HyperWorks 2012

[4]. Altair Engineering. "Altair Motion View: Pre-and Post Processing for Multi-Body Dynamics, Volume I.” HyperWorks Training Manual, 2004.

[5]. Altair Engineering. “Altair HyperMesh: Introduction to FEA: Pre-ProcessingVolume I.” HyperWorks Training Manual, 2004.

[6]. Altair Engineering. "Altair OptiStruct: Concept Design Using Topology and Topography Optimization.” HyperWorks Training Manual, 2004.

[7]. Kirpal singh: Automobile engineering(Text book) 